\title{
Combination of insulin-like growth factor-1, IGF binding protein-3, chromogranin A and prostate specific antigen can improve the detection of prostate cancer
}

\author{
Saleh Ahmed Kamaleldin Saleh ${ }^{1,3}$, Heba Mohamed Adly ${ }^{1}$, Anmar Mohammed Nassir ${ }^{2}$ \\ ${ }^{1}$ Biochemistry Department, Faculty of Medicine, Umm Al Qura University, Al Awali, Makkah 24381, Saudi Arabia. \\ ${ }^{2}$ Department of Surgery, Faculty of Medicine, Umm Al Qura University, Al Awali, Makkah 24381, Saudi Arabia. \\ ${ }^{3}$ Oncology Diagnostic Unit, Faculty of Medicine, Ain Shams University, Abasseya, Cairo 11591, Egypt.
}

Correspondence to: Dr. Saleh Ahmed Kamaleldin Saleh, Biochemistry Department, Faculty of Medicine, Umm Al Qura University, Al Awali, Makkah 24381, Saudi Arabia. E-mail: Saleh-A-S@hotmail.com

How to cite this article: Saleh SAK, Adly HM, Nassir AM. Combination of insulin-like growth factor-1, IGF binding protein-3, chromogranin A and prostate specific antigen can improve the detection of prostate cancer. J Cancer Metastasis Treat 2017;3:82-9.

Article history:

Received: $13-03-2017$

Accepted: 26-04-2017

Published: 24-05-2017

Key words:

Prostate cancer,

benign prostatic hyperplasia,

insulin-like growth factor-1,

IGF binding protein-3,

chromogranin A

\begin{abstract}
Aim: Prostate cancer ( $\mathrm{PCa}$ ) is the second most prevalent male cancer worldwide and designated the sixth most frequent male cancer in Arab countries. Although prostate specific antigen (PSA) has become the best and most valuable biomarker for screening of PCa, elevated levels of PSA can reflect the presence of malignant cells but can overlap with benign prostatic diseases. There is a necessity to develop and improve current tools for early detection and diagnosis of PCa. This study was done to evaluate the validation of serum insulin-like growth factor-1 (IGF-1), IGF binding protein-3 (IGFBP-3), chromogranin A $(\mathrm{CgA})$ and combination with PSA in treatment of benign prostatic hyperplasia (BPH) and PCa patients. Methods: The study included 72 patients with $\mathrm{PCa}, 70 \mathrm{BPH}$ patients and 56 healthy male subjects of matched age. Full history and clinical data were recorded for all subjects. Results: Serum PSA attained sensitivity of $84 \%$ at $82 \%$ specificity with an accuracy of $83 \%$, although IGF-1, IGFBP-3 and CgA did not recognize PCa patients. Conclusion: Combinations of IGF-1 and IGFBP-3 biomarkers with PSA were effectively differentiated between $\mathrm{PCa}$ and control groups as well as improving the overall value of sensitivity, specificity and diagnostic accuracy of PCa to $85 \%$ and $86 \%$ for IGF-1/PSA and IGFP-3/PSA respectively.
\end{abstract}

\section{INTRODUCTION}

Prostate cancer $(\mathrm{PCa})$ is ranked the second most prevalent male cancer worldwide ${ }^{[1]}$ and is currently the sixth frequent male cancer in Arab countries. ${ }^{[2]}$
The annual worldwide estimate is 1.1 million new diagnosed PCa male patients, representing $15 \%$ of all male cancers and about $70 \%$ of the cases occurring in developed countries. PCa represents the fifth most common cause of male cancer death, accounting for

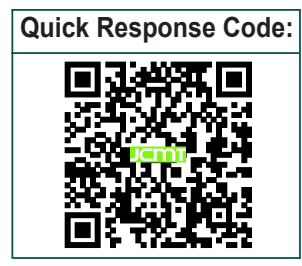


$6.6 \%$ of overall male deaths. ${ }^{[3]}$ In the United States, about 161,000 new PCa cases are anticipated in 2017 along with approximately 26,700 PCa deaths. ${ }^{[4]}$ Radical prostatectomy and radiotherapy are still curative therapeutic options for $\mathrm{PCa}$, but are restricted to organ-confined tumors. Therefore, the successful treatment of $\mathrm{PCa}$ depends on detection of the disease at its earliest stages. There is a necessity to improve current methods for early detection and/or diagnosis of $\mathrm{PCa}$ and to distinguish men at risk for carcinogenesis. ${ }^{[5]}$ Screening can detect disease in its early or asymptomatic stage; in addition, screening tests of malignant tumors must have high sensitivity to detect the disease with sufficient specificity to protect patients with false-positive results from uncalled-for diagnostic interventions. ${ }^{[6]}$

A single polypeptide, prostate specific antigen (PSA), exists in diverse molecular forms. It occurs in either normal or malignant prostatic tissue. About $70-90 \%$ of serum PSA combines with serum protein inhibitor, alpha 1 antichymotrypsin, and the rest remains unbound in free form (fPSA). Measurements of total and free/total PSA ratio are common analyses in diagnosing $\mathrm{PCa}$. The lower the f/tPSA ratio, the higher the likelihood of malignancy. The protocol for PCa screening may involve PSA analysis and digital rectal examination. Trans-rectal ultrasonography has been associated with an increased false positive rate, making it not ideal screening tool. It has been recommended that, starting at age 50 years, a routine check-up with PSA analysis and digital rectal examination be carried out annually for men at high risk. Single polypeptide PSA is expressed in normal, benign and malignant prostatic tissues but not in any other human tissue. ${ }^{[7]}$ Although the introduction of PSA related PCa screening and PSA has become the best and most valuable biomarker for screening, detection, staging and monitoring of $\mathrm{PCa}$; there are challenges. For example, elevated levels of PSA can reflect the presence of malignant cells but can also be related to non-malignant prostate disorders like benign prostatic hyperplasia (BPH), infection or chronic inflammations. ${ }^{\left[{ }^{[8]}\right.}$ Increased serum PSA levels have been seen in patients with $\mathrm{PCa}$, as well as in BPH and prostatitis, producing a high rate of false-positive cases. There also remains a wide overlap between $\mathrm{PCa}$ and $\mathrm{BPH}$, particularly in patients with marginally increased PSA concentrations, in the range of $4-10 \mathrm{ng} / \mathrm{mL}$, a range which is said to be a "grey zone" where there is a dilemma in differentiation between benign and malignant prostatic diseases; this dilemma has strengthened the necessity to improve PCa specificity by developing, combining and validating other diagnostic biomarkers with consideration of the sensitivity. ${ }^{\left[{ }^{9]}\right.}$ Consequently, the clinical value of early detection of PCa has induced the search of many novel PSA-based diagnostic markers that might, singly or in combination, improve discrimination between $\mathrm{PCa}$ and $\mathrm{BPH}$ leading to help minimize the frequency of unnecessary and invasive biopsies. ${ }^{[10]}$

The cell cycles of common human cells are tightly controlled and coordinated by intra-and extracellular signals, working in harmony and congruence to appropriately regulate cell proliferation, deterioration and apoptosis. As the combined signals of growth and inhibition boost proliferation, the cell attains mitosis. ${ }^{[11]}$ Insulin-like growth factors (IGFs) are important moderators of growth, development, and survival. They are synthesized by virtually any bodily tissue, and their action is accomplished by a network of complex molecules, including binding proteins, proteases and receptors, which all comprise the IGF system. ${ }^{[12]}$ IGF-1 and IGF binding protein-3 (IGFBP-3) play a pivotal function in the regulation of growth; controlling cellular proliferation and apoptosis. Circulating IGF-1 binds to the IGF-1 receptor and acts as a stimulus of signal transduction reactions, promoting proliferation and increased survival of cells. Such signalling components and reactions are fundamental to the tumorigenesis processes. ${ }^{[13]}$ The IGFBPs family exists in six different types; all with high affinity for IGF-1. IGFBP-3 is the superabundant type that influences serum levels of IGFs and has the highest affinity to IGF-1. ${ }^{[11]}$ Although IGFBPs are mainly synthesized in the liver, they can be expressed in many other normal and cancerous tissues such as lung, breast, and ovarian cancers. IGFBPs may impact carcinogenesis by various mechanisms. They regulate bioavailability of circulating IGF-1/2 as well as their activity and transportation mechanisms to target tissues ${ }^{[14]}$ In many types of cancers, IGF-1 and IGFBP-3 have been related to tumor grade and stage as well as disease progression. ${ }^{[15]}$ Most circulating IGF-1 (99\%) is bound to IGFBPs; less than $1 \%$ is carried in the unbound state in the circulation. IGFBP-3 is the most abundant IGFBP in the circulation and is produced by many types of cells, and is believed to regulate the availability of IGF- ${ }^{[16]}$ by impairing IGF action and inhibiting cell growth by blocking free IGFs or through IGF-independent mechanisms. ${ }^{[17]}$ Moreover, IGFBP-3 has been found to elevate levels of the cell-cycle inhibitor p21/WAF1, leading to growth arrest in PCa cells. ${ }^{[18]}$ Many studies have shown the correlation between IGF-1 and PCa risk, and they have demonstrated the inclusion of the IGF network in the early stages of prostate carcinogenesis ${ }^{[19]}$ and other studies have found increased circulating IGF-1 and decreased IGFBP-3 levels correlated with an excess 
risk of PCa development. However, in these studies, PSA remains the best $\mathrm{PCa}$ predictor. ${ }^{[20]}$ Another metaanalysis research found a positive relation between IGFBP-3 and PCa risk. However, the controversy over the contradicted results of IGF-1 and IGFBP-3 in these studies has been attributed to many factors such as race, ${ }^{[21]}$ study design and assay features. ${ }^{[22]}$

Chromogranin $\mathrm{A}(\mathrm{CgA})$ is a member of the granin family, of $439 \mathrm{kDa}$ glycoprotein, and exists in the secretory dense-core granules that contribute to the storage of peptide hormones and catecholaminein all endocrine and neuroendocrine (NE) cells. Thus, it can be released from NE cells in a heterogeneous circulating molecular form and is considered one of the most abundant components of secretory granules. ${ }^{[23]}$ While its function is unknown, through previous decades a growing body of evidence has suggested that $\mathrm{CgA}$ is released in abnormal amounts by many malignant NE cells, which may influence different components of the tumor stroma and engage with the regulation of tumor growth and progression. However, increased blood $\mathrm{CgA}$ levels have been established as a useful indicator in the diagnosis of many NE tumors, but the use of this marker for clinical management is still controversial. ${ }^{[23,24]}$ Therefore, research has been dedicated to its prognostic and diagnostic importance, but with little supporting evidence for its use beyond common screening methods. ${ }^{[8]}$ Several studies have reported that elevated $\mathrm{CgA}$ concentrations are associated with high-grade and advanced stage PCa. Some studies have indicated that increased serum CgA exceeded PSA increase as a marker of progression to hormone-refractory disease. Therefore, it is possible to use $\mathrm{CgA}$ to monitor metastatic $\mathrm{PCa}$ patients under androgen blockade. ${ }^{[25]}$ Some indicate $\mathrm{CgA}$ utility in early diagnosis, particularly when used in combination with free/total PSA ratio, ${ }^{[26]}$ however, some studies found that $\mathrm{CgA}$ does not precisely differentiate malignant disease. ${ }^{[27]}$ Similar debate occurs regarding $\mathrm{CgA}$ and tumor features ${ }^{[28]}$ and $\mathrm{CgA}$ does not show any advantage in the prognosis of $\mathrm{PCa}$ recurrence after radical prostatectomy or radiotherapy. [29] Inconsistencies may be attributed to the transient and reversible process of neuroendocrine differentiation (NED) in most malignant prostate tumors; thus, these NE molecules are not constantly detectable..$^{[5,30]}$

This study is dedicated to evaluate the validity of IGF-1, IGFBP-3, CgA and combination with PSA in diagnosis of patients with localized and metastatic $\mathrm{PCa}$. The secondary objective was to compare the advantage of these markers in differentiation of $\mathrm{PCa}$ patients.

\section{METHODS}

This study included 72 patients with PCa (mean age $70.8 \pm 5.3$ years), $70 \mathrm{BPH}$ patients (mean age $69.5 \pm$ 7.3 years) and 56 healthy males (mean age $67.3 \pm 7.2$ years) were randomly recruited among the volunteers of matched socioeconomic conditions and who did not have any known significant disease. Full history and clinical data were recorded for all subjects, and $\mathrm{PCa}$ patients were classified into localized PCa $(n=54)$ and metastatic PCa $(n=18)$. BPH and healthy male individuals $(n=126)$ were grouped as control. Patients with $\mathrm{PCa}$ underwent digital rectal examination, transrectal ultrasonography, guided biopsy of the prostate, computed tomography scanning of the pelvis, bone scanning, and histopathological examination to assess metastatic disease and determine disease stage.

\section{Blood samples}

A $10 \mathrm{~mL}$ blood sample was drawn in the morning after overnight fasting from healthy subjects and one week following digital rectal examination for patients with prostatic diseases at the time of diagnosis.

Serums of blood samples were separated and stored at $-20^{\circ} \mathrm{C}$ in a deep freeze until the date of analysis. Serum levels of IGF-1, IGFBP-3, CgA, total (tPSA) and free PSA (fPSA) were measured by chemiluminescence ELISA technique IMMULITE, DPC (Diagnostic Products Corporation, Los Angeles, CA, USA).

\section{Statistical analysis}

Serum concentrations of CgA, IGF-1, IGFBP-3, tPSA and $\mathrm{FPSA}$ in addition to combination among parameters were expressed as arithmetic mean and standard deviation. Statistical analysis was accomplished by using the statistical package IBM SPSS V20. Data between the groups were compared and the statistical significance of mean values was determined by applying independent sample $t$-test and Mann-Whitney test. The significance level was established at the $P$ value of $<0.05$. The validity (sensitivity and specificity), accuracy of each parameter and ratios thereof were calculated by area under curve (AUC) in receiver operating characteristics (ROC) curve analysis.

\section{RESULTS}

A total of 54 cases of localized PCa patients, mean age $70.3 \pm 6.3$ years, and 18 metastatic patients, mean age $71.1 \pm 5.5$ years, were grouped as PCa patients with a mean age of $70.8 \pm 5.3$ years $(P>0.05)$. Seventy BPH patients, mean age $69.5 \pm 7.3$ years, and 56 healthy male individuals, mean age $67.3 \pm 7.2$ years, were also included as a control group with a mean age of $68.3 \pm$ 


\section{5 years $(P>0.05)$ as represented in Table 1.}

Serum tPSA levels were significantly higher in the $\mathrm{PCa}$ group, $34.3 \pm 21.1 \mathrm{ng} / \mathrm{mL}$, as compared to the control group, $2.8 \pm 1.9 \mathrm{ng} / \mathrm{mL}(P<0.005)$ [Table 1], and the study showed significant differentiation between localized and metastatic PCa. Similarly, the f/tPSA ratio exhibited a significant difference among control, localized and metastatic PCa groups $(P<0.005$, Table 1; Figure $1 \mathrm{~A}$ and $\mathrm{B}$ ). Surprisingly, while serum IGF-1 level showed no statistical difference between studied groups, as it represented $155.0 \pm 44.2 \mathrm{ng} / \mathrm{mL}$ in PCa group compared to $148.4 \pm 36.1 \mathrm{ng} / \mathrm{mL}$ in control group $(P>0.05)$ [Table 1 and Figure $1 \mathrm{C}$ ], its combination with tPSA as IGF-1/tPSA ratio could differentiate significantly between $\mathrm{PCa}, 148.4 \pm 36.1$, and control groups, 64.8 $\pm 22.3(P<0.005)$ [Table 1 and Figure 1C]. Similarly, mean serum IGFBP-3 and CgA did not statistically differentiate between the PCa and control groups, as IGFBP-3 represented $3,052 \pm 319 \mathrm{ng} / \mathrm{mL}$ and 3,154 \pm $371 \mathrm{ng} / \mathrm{mL}$ in PCa and control groups respectively $(P<$ 0.05 , Table 1 and Figure 1D) and CgA represented 65.4 $\pm 30.3 \mathrm{ng} / \mathrm{mL}$ and $62.1 \pm 29.8 \mathrm{ng} / \mathrm{mL}$ in PCa and control groups respectively $(P<0.05$, Table 1 and Figure 1D). On the other hand, statistical significance was noted for their ratios with IPSA, (IGFBP-3/tPSA and CgA/ tPSA ratios), in distinguishing $\mathrm{PCa}$ and control groups $(P<0.005$, Table 1 and Figure 1E).

The validity (sensitivity and specificity), and accuracy of each parameter for prediction of $\mathrm{PCa}$ occurrence were calculated by AUC in ROC curve analysis of prediagnostic serum concentrations of tPSA, FPSA, IGF-I, IGFBP-3, and CgA and ratios thereof, for 72 patients with $\mathrm{PCa}$ and 126 control individuals. The AUC for tPSA, IGF-I, IGFBP-3, and CgA was 0.83, 0.58, 0.55 and 0.56 respectively. The AUC for f/tPSA, IGF1/tPSA, IGFP-3/tPSA and CgA/tPSA was $0.76,0.85$, 0.86 and 0.74 , respectively. Thus, the combination of PSA with, IGF-1, IGFBP-3, and CgA improved the sensitivity, specificity and diagnostic accuracy for $\mathrm{PCa}$ patients [Table 2 and Figure 2].

\section{DISCUSSION}

The successful treatment of $\mathrm{PCa}$ depends on detection of the disease at its earliest stages. Since $\mathrm{PCa}$ is a heterogeneous disease, there is a need for supplementary biomarkers that add useful information and correctly prognosticate the existence and progression of $\mathrm{PCa}$ to eliminate unnecessary invasive biopsies and aggressive diagnostic tools, decrease morbidity rates, and reduce unnecessary expenses. Thus, many prospective $\mathrm{PCa}$ biomarkers will continue to develop and expand to improve and provide more diagnostic information and supplement PSA testing. A diversity of diagnostic and prognostic markers had been explored in different body fluids and tissue samples, although their clinical use still need further validation. The ideal PCa biomarkers should be prostate specific, readily detectable in the body fluids, reproducibly measured and analysed, and can effectively differentiate among normal, benign and cancerous prostatic diseases as well as have cogent

Table 1: Serum levels of selected parameters in study population (mean \pm SD)

\begin{tabular}{|c|c|c|c|c|c|c|c|}
\hline \multirow{2}{*}{ Parameter } & \multicolumn{3}{|c|}{ Control groups } & \multicolumn{3}{|c|}{ PCa groups } & \multirow{2}{*}{$P$ value } \\
\hline & BPH & Healthy & Total & Localized & Metastatic & Total & \\
\hline Number $(n)$ & 70 & 56 & 126 & 54 & 18 & 72 & - \\
\hline Age (year) & $69.5 \pm 7.3$ & $67.3 \pm 7.2$ & $68.3 \pm 6.5$ & $70.3 \pm 6.3$ & $71.1 \pm 5.5$ & $70.8 \pm 5.3$ & $>0.05$ \\
\hline IGF-1 (ng/mL) & $149.8 \pm 35.6$ & $146.5 \pm 37.4$ & $148.4 \pm 36.1$ & $154.3 \pm 44.2$ & $157.6 \pm 47.7^{a}$ & $155.0 \pm 44.2^{b}$ & $>0.05^{a}$ \\
\hline IGFBP-3 (ng/mL) & $3,125 \pm 372$ & $3,174 \pm 363$ & $3,154 \pm 371$ & $3,082 \pm 311$ & $2,925 \pm 346^{a}$ & $3,052 \pm 319^{b}$ & $>0.05^{\mathrm{a}}$ \\
\hline $\mathrm{CgA}(\mathrm{ng} / \mathrm{mL})$ & $62.3 \pm 27.6$ & $61.9 \pm 30.3$ & $62.1 \pm 29.8$ & $64.0 \pm 29.6$ & $67.6 \pm 33.9^{a}$ & $65.4 \pm 30.3^{b}$ & $>0.05^{\mathrm{a}}$ \\
\hline tPSA (ng/mL) & $3.7 \pm 2.0$ & $1.6 \pm 0.8$ & $2.8 \pm 1.9$ & $27.8 \pm 15.4$ & $52.3 \pm 22.6^{a}$ & $34.3 \pm 21.1^{b}$ & $\begin{array}{l}<0.005^{a} \\
<0.005^{b}\end{array}$ \\
\hline $\mathrm{f} / \mathrm{tPSA}$ & $0.24 \pm 0.02$ & $0.28 \pm 0.03$ & $0.26 \pm 0.02$ & $0.15 \pm 0.02$ & $0.11 \pm 0.01^{a}$ & $0.13 \pm 0.02^{b}$ & $\begin{array}{l}<0.005^{\mathrm{a}} \\
<0.005^{\mathrm{b}}\end{array}$ \\
\hline IGF-1/tPSA & $49.7 \pm 17.6$ & $102.8 \pm 37.1$ & $64.8 \pm 22.3$ & $6.7 \pm 2.9$ & $4.1 \pm 2.4^{a}$ & $4.9 \pm 2.7^{b}$ & $<0.005^{\mathrm{a}}$ \\
\hline IGFP-3/tPSA & $893 \pm 352$ & $1,710 \pm 524$ & $1,310 \pm 422$ & $253 \pm 197$ & $186 \pm 164^{a}$ & $212 \pm 178^{b}$ & $\begin{array}{l}>0.05^{\mathrm{a}} \\
<0.005^{\mathrm{b}}\end{array}$ \\
\hline $\mathrm{CgA} / \mathrm{tPSA}$ & $14.6 \pm 5.4$ & $24.7 \pm 9.6$ & $20.3 \pm 8.5$ & $3.1 \pm 2.1$ & $2.2 \pm 1.6^{a}$ & $2.8 \pm 2.0^{b}$ & $\begin{array}{l}>0.05^{\mathrm{a}} \\
<0.005^{\mathrm{b}}\end{array}$ \\
\hline IGF-I/fPSA & $348 \pm 196$ & $372 \pm 228$ & $364 \pm 221$ & $326 \pm 216$ & $296 \pm 185^{a}$ & $311 \pm 201^{b}$ & $\begin{array}{l}>0.05^{\mathrm{a}} \\
>0.05^{\mathrm{b}}\end{array}$ \\
\hline IGFBP-3/fPSA & $3,727 \pm 1,739$ & $3,918 \pm 1,865$ & $3,811 \pm 1,788$ & $3,395 \pm 2,216$ & $3,210 \pm 1,984^{a}$ & $3,304 \pm 2,107^{b}$ & $\begin{array}{l}>0.05^{\mathrm{a}} \\
>0.05^{\mathrm{b}}\end{array}$ \\
\hline
\end{tabular}

SD: standard deviation; PCa: prostate cancer; BPH: benign prostatic hyperplasia; IGF-1: insulin-like growth factor-1; IGFBP-3: IGF binding protein-3; CgA: chromogranin A; tPSA: total prostate specific antigen; f/tPSA: free/total prostate specific antigen; ${ }^{\text {a }}$ : comparison between the localized and metastatic in PCa groups; ${ }^{\text {b }}$ : comparison between total $\mathrm{PCa}$ groups and control groups 


\section{correlation to clinical data. ${ }^{[5,11]}$}

In the present study, serum tPSA and f/tPSA were significantly higher in the $\mathrm{PCa}$ than in the control groups and they can significantly be influenced by the tumor metastasizing. IGF-1 serum level was slightly increased and IGFBP-3 level was slightly decreased in patients with $\mathrm{PCa}$, but they did not differentiate between PCa patients and control individuals; thus, no association of $\mathrm{PCa}$ risk were observed with prediagnostic serum concentrations of IGF-1, IGFBP-3 which may be attributed to the function of IGFBP-3 as a substrate for PSA. This is a member of the kallikrein family of serine protease ${ }^{[31]}$ and it is assumed that rising PSA levels during the natural history of $\mathrm{PCa}$ enhances the disease progression by proteolytically cleaving IGFBP-3, thereby increasing the amount of bioavailable IGF-1. ${ }^{[32]}$ Previous study on Arab males indicated that IGF-1 and IGFBP-3 reached their peak levels during adolescence and gradually lowered with age. ${ }^{[33]}$ IGFBP-3, the most prevalent form of the IGFBPs, has been linked with prostatic growth. About $75 \%$ of IGF-1 is bound to IGFBP-3, while $20-25 \%$ is bound to the other binding proteins (IGFBP-1, 2, 4 and 5 ), and less than $1 \%$ is carried in the unbound state in the circulation. ${ }^{[16]}$ Therefore, relative IGFBP-3 concentrations may affect serum and likely prostatic tissue levels of IGF-1. Importantly, although the IGFBP3-IGF-1 complex is a high molecular weight protein that cannot diffuse into tissues, complexes of IGF-1 and other IGFBPs have a lower molecular weight and can traverse the capillary membrane into tissues. ${ }^{[16,34]}$ Consequently, a decline of IGFBP-3 levels may give rise to an intension bind of IGF-1 to other IGFBPs, high diffusion into tissues, and an elevated tissue IGF1 levels, leading to increased prostatic growth. Some
A
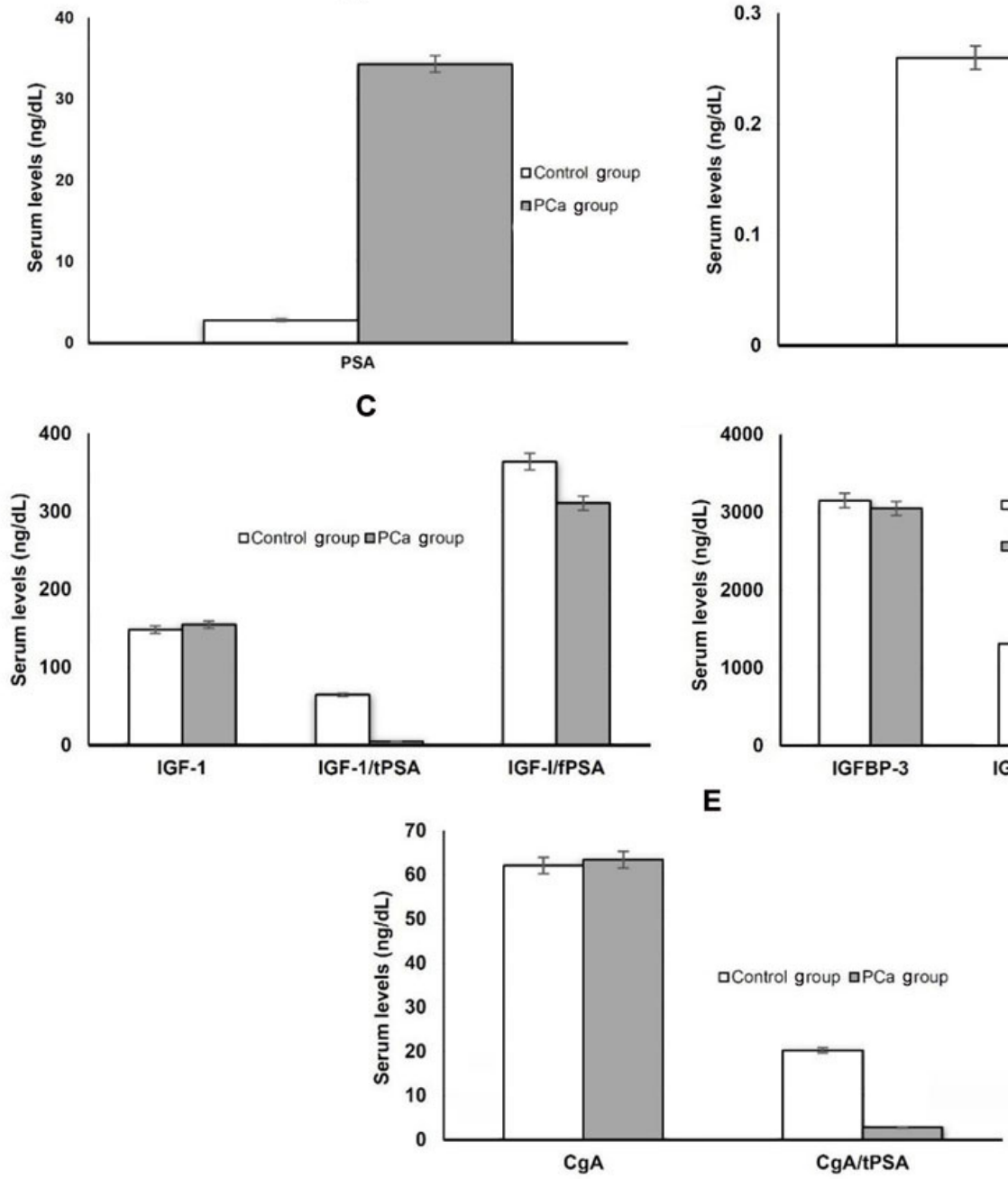

B
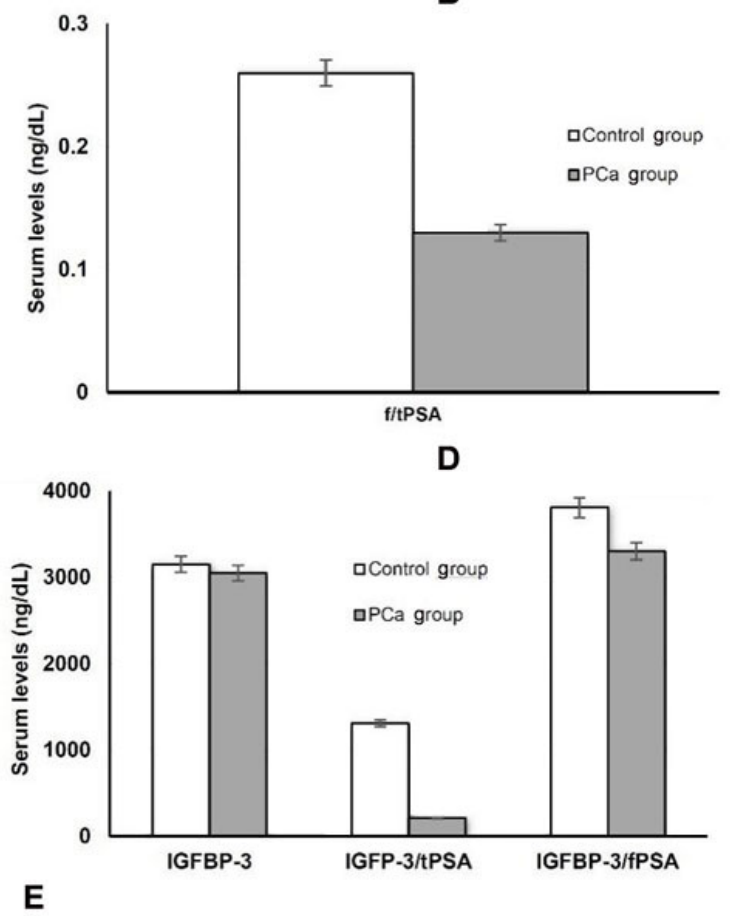

Figure 1: (A) Mean levels of tPSA in PCa and control groups; (B) mean levels of f/tPSA ratio in PCa and control groups; (C) mean levels of IGF-1, IGF-1/tPSA and IGF-1/fPSA ratios in PCa and control groups; (D) mean levels of IGFBP-3, IGFBP-3/tPSA and IGFBP-3/fPSA ratios in PCa and control groups; $(E)$ mean levels of $\mathrm{CgA}$ and $\mathrm{CgA} / \mathrm{tPSA}$ ratios in $\mathrm{PCa}$ and control groups. tPSA: total prostate specific antigen; PCa: prostate cancer; f/tPSA: free/total prostate specific antigen; IGF-1: insulin-like growth factor-1; IGFBP-3: IGF binding protein-3; CgA: chromogranin A 


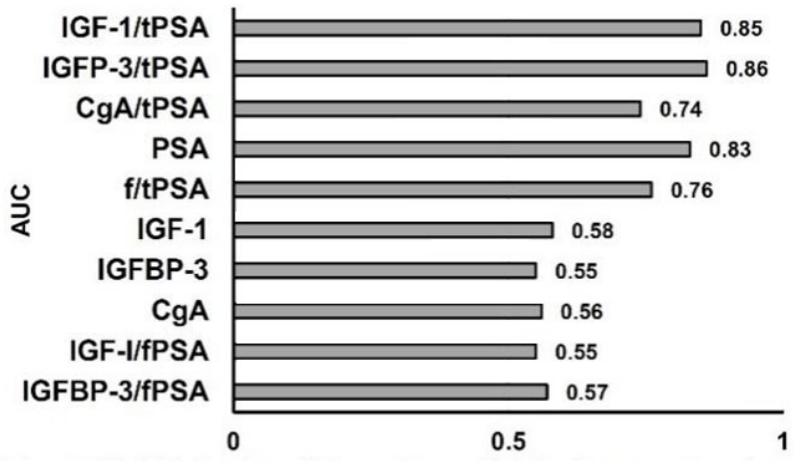

Figure 2: Validity (sensitivity and specificity) of parameters for prediction of future PCa occurrence, estimated by AUC. PCa: prostate cancer; AUC: area under curve; IGF-1: insulin-like growth factor-1; IGFBP-3: IGF binding protein-3; CgA: chromogranin A; tPSA: total prostate specific antigen; f/tPSA: free/total prostate specific antigen

Table 2: Validity* of selected markers in PCa detection

\begin{tabular}{lccc}
\hline Parameter & AUC & $\mathbf{9 5 \%} \mathbf{C l}$ & $\boldsymbol{P}$ value \\
\hline IGF-1 & 0.58 & $0.51-0.66$ & $>0.05$ \\
IGFBP-3 & 0.55 & $0.48-0.63$ & $>0.05$ \\
GgA & 0.56 & $0.49-0.64$ & $>0.05$ \\
PSA & 0.83 & $0.76-0.90$ & $<0.005$ \\
f/tPSA & 0.76 & $0.69-0.83$ & $<0.005$ \\
IGF-1/tPSA & 0.85 & $0.78-0.92$ & $<0.005$ \\
IGFP-3/tPSA & 0.86 & $0.79-0.93$ & $<0.005$ \\
CgA/tPSA & 0.74 & $0.67-0.82$ & $<0.05$ \\
IGF-I/fPSA & 0.55 & $0.48-0.63$ & $>0.05$ \\
IGFBP-3/fPSA & 0.57 & $0.49-0.64$ & $>0.05$ \\
\hline
\end{tabular}

*Validity (sensitivity and specificity) for prediction of $\mathrm{PCa}$ occurrence, estimated by AUC in ROC curve analysis of prediagnostic serum concentrations of tPSA, fPSA, IGF-I, IGFBP-3, and $\mathrm{CgA}$ and ratios thereof, for 72 patients with $\mathrm{PCa}$ and 126 control subjects. PCa: prostate cancer; ROC: receiver operating characteristics; AUC: area under curve; $\mathrm{BPH}$ : benign prostatic hyperplasia; IGF-1: insulin-like growth factor-1; IGFBP-3: IGF binding protein-3; $\mathrm{CgA}$ : chromogranin A; tPSA: total prostate specific antigen; f/tPSA: free/total prostate specific antigen

previous studies revealed that elevated concentrations of IGF-1 may increase the risk of some cancers, ${ }^{[35,36]}$ but results with respect to PCa have been discordant with other reports which revealed null associations similar to present study. ${ }^{[37,38]}$ As with the results of IGF-1 and IGFBP-3, although there was no statistical difference between $\mathrm{CgA}$ levels of $\mathrm{PCa}$ patients and control groups, $\mathrm{CgA}$ was slightly increased in patients with PCa than control groups. CgA is an excellent indicator of NE cells and of NED in PCa either in tissue or serum. The detection of $\mathrm{CgA}$ in the blood of patients with PCa indicates a NED, either of a primary tumour or an association with metastases. ${ }^{[39]}$ Tumors with NE features have displayed more aggression and are more resistant to hormone therapy. ${ }^{[25]}$

Some studies have claimed that $\mathrm{CgA}$ is an independent prognostic marker for $\mathrm{PCa},{ }^{[40]}$ while others have conflicted with these findings. ${ }^{[29,41]}$ No $\mathrm{PCa}$ predictive values were seen for IGF-1, IGFBP-3 or CgA; AUC were $0.58,0.55$ and 0.56 , respectively. Similarly, some earlier reports found disappointing results for these biomarkers. ${ }^{[42]}$ Although the negative findings of the present study regarding IGF-1, IGFBP-3 or CgA serum levels in differentiating between the $\mathrm{PCa}$ and control groups; are notable, analysing the combination of these markers with PSA either in the PCa and control groups revealed that their combinations with serum tPSA level, (IGF-1/tPSA, IGFBP-3/tPSA and CgA/tPSA) were differentiated significantly among $\mathrm{PCa}, \mathrm{BPH}$ patients and healthy individuals. These combinations could, potentially, effectively distinguish PCa patients from non-malignant individuals. Also, IGF-1/tPSA ratio can significantly differentiate between localized and metastatic PCa. Moreover, in our study, the ratios of IGF-1/tPSA and IGFBP-3/tPSA (AUC of 0.85 and 0.86 , respectively) improved cancer detection, in comparison with PSA or f/tPSA ratio, (AUC of 0.83 and 0.76 respectively). Thus it would seem that circulating IGF-1 and IGFBP-3 concentrations are unlikely to be useful in differentiating patients with $\mathrm{BPH}$ from those with $\mathrm{PCa}$, but their combinations with serum PSA level (IGF-1/PSA and IGFBP-3/PSA ratios) have improved the validity and correlation with the progression and clinical course of the disease. The strong correlation between the defective regulation of the IGF network and prostate carcinogenesis has been investigated previously by measurement of another member of the IGF family, IGF-2, in patients with PCa and BPH. Also no significant association was found between PSA and IGF-2 levels. However, the combination of PSA and IGF-2 improved the prognosis and discrimination of $\mathrm{PCa}$ and $\mathrm{BPH} .{ }^{[43]}$

The successful treatment of PCa depends on detection of the disease at its earliest stages. There is significant evidence for some novel PCa biomarkers to overcome the limitations of PSA; identifying these markers will allow more appropriate screening for early disease. However, few biomarkers have been appropriately validated and/or involved in clinical approach. To date, conflicting and insufficient data have indicated that there is still no biomarker likely to attain the desirable level of sensitivity and specificity. Potentially, combining use of biomarkers may improve the diagnostic accuracy of PCa which would impact treatment outcome.

In conclusion, although circulating IGF-1, IGFBP-3 and $\mathrm{CgA}$ are unlikely to be useful in differentiating healthy individuals or patients with BPH from those with $\mathrm{PCa}$, or in identifying $\mathrm{PCa}$ metastasis, the combination of IGF-1 and IGFBP-3 with PSA has improved the overall sensitivity, specificity and diagnostic accuracy of PSA for prediction of the disease. Further prospective studies are needed concerning the correlation of 
these serum markers and the aggressiveness of the $\mathrm{PCa}$, either in terms of the pathological stage or of the Gleason score.

\section{Authors' contributions}

All authors equally contributed to this study.

\section{Financial support and sponsorship}

None.

\section{Conflicts of interest}

There are no conflicts of interest.

\section{Patient consent}

Patient consent was obtained from all participants. All participants were informed of the aim and procedures and were assured that they could discontinue their participation in the study without any effect on the medical care provided to them.

\section{Ethics approval}

The Ethical Research Committee at the Faculty of Medicine, Umm Al Qura University, and affiliated hospitals approved this study. Informed consent was obtained from all patients and healthy subjects; the aim of the study and the procedures that would be required were described to them beforehand. All subjects were assured that they could choose to discontinue their participation in the study without jeopardizing the medical care being given to them, including treatment and follow-up.

\section{REFERENCES}

1. Cancer Facts and Figures 2017. Atlanta, GA: American Cancer Society; 2017.

2. Mahmood A, Te OB, Urcia JC, Khan A. Tumor registry annual report 2011. Riyadh: King Faisal Specialist Hospital and Research Center; 2012.

3. International Agency for Research on Cancer (IARC) (2012) [cited 2016 December 9]. Prostate Cancer, Estimated Incidence, Mortality and Prevalence Worldwide. Available from: http://globocan.iarc.fr/old/ FactSheets/cancers/prostate-new.asp\#INCIDENCE. [Last accessed on May 16, 2017]

4. Siegel RL, Miller KD, Jemal A. Cancer statistics, 2017. CA Cancer J Clin 2017;67:7-30

5. Ramírez ML, Nelson EC, Evans CP. Beyond prostate-specific antigen: alternate serum markers. Prostate Cancer Prostatic Dis 2008;11:216-29.

6. Perkins GL, Slater ED, Sanders GK, Prichard JG. Serum tumor markers. Am Fam Physician 2003;68:1075-82.

7. Theodorescu D, Krupski TL (2009) [Cited 2016 December 12]. Prostate Cancer: Biology, Diagnosis, Pathology, Staging and Natural History. Available from: http://emedicine.medscape.com/ article/458011-overview. [Last accessed on May 16, 2017]

8. Bensalah K, Lotan Y, Karam JA, Shariat SF. New circulating biomarkers for prostate cancer. Prostate Cancer Prostatic Dis 2008;11:112-20.

9. Stephan C, Rittenhouse H, Hu X, Cammann H, Jung K. Prostate- specific antigen (PSA) screening and new biomarkers for prostate cancer (PCa). EJIFCC 2014;25:55-78.

10. Prensner JR, Rubin MA, Wei JT, Chinnaiyan AM. Beyond PSA: the next generation of prostate cancer biomarkers. Sci Transl Med 2012;4:127rv3.

11. Weroha SJ, Haluska P. IGF system in cancer. Endocrinol Metab Clin North Am 2012;41:335-50.

12. Moschos SJ, Mantzoros CS. The role of the IGF system in cancer: from basic to clinical studies and clinical applications. Oncology 2002;63:317-32

13. Hamelers IH, Van Schaik RF, Sipkema J, Sussenbach JS, Steenbergh $\mathrm{PH}$. Insulin-like growth factor I triggers nuclear accumulation of cyclin D1 in MCF-7S breast cancer cells. $J$ Biol Chem 2002;277:47645-52.

14. Wang H, Rosen DG, Wang H, Fuller GN, Zhang W, Liu J. Insulinlike growth factor-binding protein 2 and 5 are differentially regulated in ovarian cancer of different histologic types. Mod Pathol 2006;19:1149-56.

15. Luo SM, Tan WM, Deng WX, Zhuang SM, Luo JW. Expression of albumin, IGF-1, IGFBP-3 in tumor tissues and adjacent non-tumor tissues of hepatocellular carcinoma patients with cirrhosis. World $J$ Gastroenterol 2005;11:4272-6.

16. Rajaram S, Baylink DJ, Mohan S. Insulin-like growth factor-binding proteins in serum and other biological fluids: regulation and functions. Endocr Rev 1997;18:801-31.

17. LeRoith D, Roberts CT Jr. The insulin like growth factor system and cancer. Cancer Lett 2003;195:127-37.

18. Krishnan AV, Peehl DM, Feldman D. The role of vitamin D in prostate cancer. Recent Results Cancer Res 2003;164:205-21.

19. Papatsoris AG, Karamouzis MV, Papavassiliou AG. Novel insights into the implication of the IGF-1 network in prostate cancer. Trends Mol Med 2005;11:52-5.

20. Djavan B, Amir Kazzazi A, Dulabon L, Margreiter M, Farr A, Handl MJ, Lepor H. Diagnostic strategies for prostate cancer. Eur Urol Suppl 2011;10:26-37.

21. Berrigan D, Potischman N, Dodd KW, Hursting SD, Lavigne J, Barrett JC, Ballard-Barbash R. Race/ethnic variation in serum levels of IGF-I and IGFBP-3 in US adults. Growth Horm IGF Res 2009; 19:146-55

22. Renehan AG, Zwahlen M, Minder C, O'Dwyer ST, Shalet SM, Egger M. Insulin-like growth factor (IGF)-I, IGF binding protein-3, and cancer risk: systematic review and meta-regression analysis. Lancet 2004;363:1346-53.

23. Colombo B, Curnis F, Foglieni C,Monno A, Arrigoni G, Corti A. Chromogranin A expression in neoplastic cells affects tumor growth and morphogenesis in mouse models. Cancer Res 2002;62:941-6.

24. Yang X, Yang Y, Li Z, Cheng C, Yang T, Wang C, Liu L, Liu S. Diagnostic value of circulating chromogranin a for neuroendocrine tumors: a systematic review and meta-analysis. PLoS One 2015;10:e124884.

25. Ferrero-Poüs M, Hersant AM, Pecking A, Brésard-Leroy M, Pichon MF. Serum chromogranin-A in advanced prostate cancer. BJU Int 2001;88:790-6.

26. Berruti A, Dogliotti L, Mosca A, Bellina M, Mari M, Torta M, Tarabuzzi R, Bollito E, Fontana D, Angeli A. Circulating neuroendocrine markers in patients with prostate carcinoma. Cancer 2000;88:2590-7.

27. Fracalanza S, Prayer-Galetti T, Pinto F, Navaglia F, Sacco E, Ciaccia M, Plebani M, Pagano F, Basso D. Plasma chromogranin A in patients with prostate cancer improves the diagnostic efficacy of free/total prostate-specific antigen determination. Urol Int 2005;75:57-61.

28. Grimaldi F, Valotto C, Barbina G, Visentini D, Trianni A, Cerruto $\mathrm{MA}$, Zattoni F. The possible role of chromogranin A as a prognostic factor in organ-confined prostate cancer. Int $J$ Biol Markers 2006;21:229-34. 
29. Ahlegren G, Pedersen K, Lundberg S, Aus G, Hugosson J, Abrahamsson P. Neuroendocrine differentiation is not prognostic of failure after radical prostatectomy but correlates with tumor volume. Urology 2000;56:1011-5.

30. Zitella A, Berruti A, Destefanis P, Mengozzi G, Torta M, Ceruti C, Casetta G, Mosca A, Greco A, Rolle L, Aimo G, Aroasio E, Tizzani A, Dogliotti L, Fontana D; Gruppo Oncologico Urologico Piemontese (GOUP). Comparison between two commercially available chromogranin A assays in detecting neuroendocrine differentiation in prostate cancer and benign prostate hyperplasia. Clin Chim Acta 2007;377:103-7.

31. Cohen P, Peehl DM, Rosenfeld RG. The IGF axis in the prostate. Horm Metab Res 1994;26:81-4.

32. Corrêa LL, Lima GA, Paiva HB, Silva CM, Cavallieri SA, Miranda LC, Gadelha MR. Prostate cancer and acromegaly. Arq Bras Endocrinol Metabol 2009;53:963-8.

33. Kehinde EO, Akanji AO, Mojiminiyi OA, Bashir AA, Daar AS, Varghese R. Putative role of serum insulin-like growth factor-1 (IGF1) and IGF binding protein-3 (IGFBP-3) levels in the development of prostate cancer in Arab men. Prostate Cancer Prostatic Dis 2005;8:84-90.

34. Djavan B, Waldert M, Seitz C, Marberger M. Insulin-like growth factors and prostate cancer. World J Urol 2001;19:225-33.

35. Endogenous Hormones and Breast Cancer Collaborative Group, Key TJ, Appleby PN, Reeves GK, Roddam AW. Insulin-like growth factor 1 (IGF1), IGF binding protein 3 (IGFBP3), and breast cancer risk: pooled individual data analysis of 17 prospective studies. Lancet Oncol 2010;11:530-42.

36. Roddam AW, Allen NE, Appleby P, Key TJ, Ferrucci L, Carter HB, Metter EJ, Chen C, Weiss NS, Fitzpatrick A, Hsing AW, Lacey JV Jr, Helzlsouer K, Rinaldi S, Riboli E, Kaaks R, Janssen JA, Wildhagen MF, Schröder FH, Platz EA, Pollak M, Giovannucci E, Schaefer C, Quesenberry CP Jr, Vogelman JH, Severi G, English DR, Giles GG, Stattin P, Hallmans G, Johansson M, Chan JM, Gann P, Oliver SE, Holly JM, Donovan J, Meyer F, Bairati I, Galan P. Insulin-like growth factors, their binding proteins, and prostate cancer risk: analysis of individual patient data from 12 prospective studies. Ann Intern Med 2008;149:461-71, W83-8.

37. Mikami K, Ozasa K, Nakao M, Miki T, Hayashi K, Watanabe Y, Mori M, Sakauchi F, Washio M, Kubo T, Suzuki K, Wakai K, Nakachi K, Tajima K, Ito Y, Inaba Y, Tamakoshi A; JACC Study Group. Prostate cancer risk in relation to insulin-like growth factor (IGF)-I and IGFbinding protein-3: a nested case-control study in large scale cohort study in Japan. Asian Pac J Cancer Prev 2009;10 Suppl:57-61.

38. Pham TM, Fujino Y, Kikuchi S, Tamakoshi A, Yatsuya H, Matsuda S, Yoshimura T; JACC Study Group. A nested case-control study of stomach cancer and serum insulin-like growth factor (IGF)-1, IGF-2 and IGF-binding protein (IGFBP)-3. Eur J Cancer 2007;43:1611-6.

39. Bonkhoff H. Neuroendocrine cells in benign and malignant prostate tissue: morphogenesis, proliferation, and androgen receptor status. Prostate Suppl 1998;8:18-22.

40. Sciarpa A, Voria G, Monti S, Mazzone L, Mariotti G, Pozza M, D'Eramo G, Di Silverio F. Clinical under staging in patients with prostate adenocarcinoma submitted to radical prostatectomy: predictive value of serum chromogranin A. Prostate 2004;58:421-8.

41. Appetecchia M, Meçule A, Pasimeni G, Iannucci CV, De Carli P, Baldelli R, Barnabei A, Cigliana G, Sperduti I, Gallucci M. Incidence of high chromogranin A serum levels in patients with non-metastatic prostate adenocarcinoma. J Exp Clin Cancer Res 2010;29:166.

42. Janssen JA, Wildhagen MF, Ito K, Blijenberg BG, Van Schaik RH, Roobol MJ, Pols HA, Lamberts SW, Schröder FH. Circulating free insulin-like growth factor (IGF)-I, total IGF-I, and IGF binding protein-3 levels do not predict the future risk to develop prostate cancer: results of a case-control study involving 201 patients within a population-based screening with a 4-year interval. J Clin Endocrinol Metab 2004;89:4391-6.

43. Trojan L, Bode C, Weiss C, Mayer D, Grobholz R, Alken P, Michel MS. IGF-II serum levels increase discrimination between benign prostatic hyperplasia and prostate cancer and improve the predictive value of PSA in clinical staging. Eur Urol 2006;49:28692; discussion 292 